\title{
APRESENTAÇÃO: A FILOSOFIA AFRICANA E AFRODIASPÓRICA NO BRASIL
}

\author{
Adilbênia Freire Machado ${ }^{l}$ \\ Aline Cristina Oliveira do Carmo ${ }^{2}$ \\ Eduardo David de Oliveira ${ }^{3}$ \\ Julvan Moreira de Oliveira ${ }^{4}$ \\ Renato Noguera ${ }^{5}$ \\ Wanderson Flor do Nascimento ${ }^{6}$
}

Uma das maiores dificuldades da Filosofia no Brasil diz respeito à sua não preocupação com os pensamentos africanos e afro-diaspóricos, enquanto os estudos e

\footnotetext{
${ }^{1}$ Doutora em Educação (UFC); Mestra em Educação (UFBA); Bacharela e Licenciada em Filosofia (UECE). Faz parte do NACE (Núcleo das Africanidades Cearenses / UFC), AAFROCEL (Academia Afrocearense de Letras), GRIÔ: cultura popular, ancestralidade africana e educação (UFBA), ABPN (Associação Brasileira de Pesquisadores Negr@s) e Rede Brasileira de Mulheres Filósofas. E-mail: adilmachado@yahoo.com.br

${ }^{2}$ Doutora em Filosofia pela Universidade do Estado do Rio de Janeiro (UERJ), bacharel em direito pela Universidade Federal do Estado do Rio de Janeiro (UNIRIO), com diploma de postítulo em Direitos Humanos e Processos de Democratização pela Faculdade de Direito da Universidade do Chile (UChile). Atualmente é docente-pesquisadora do Departamento de Filosofia do Colégio Pedro II, membro do Núcleo de estudos afro-brasileiros e indígenas da mesma instituição (NeabiCp2) e uma das coordenadoras da área de Filosofia Africana e Afrodiaspórica da ABPN. E-mail: alinecarmo84@gmail.com
}

\footnotetext{
${ }^{3}$ Filósofo, Antropólogo, Educador e Poeta, é professor na FACED-UFBA, coordena a Linha de Pesquisa Conhecimento e Cultura do Doutorado em Difusão do Conhecimento - DMMDC, coordenador do Grupo de Pesquisa RedeAfricanidades e um dos coordenadores da área de Filosofia Africana e Afrodiaspórica da ABPN. E-mail: afroduda@gmail.com
}

\footnotetext{
${ }^{4}$ Professor do Programa de Pós-graduação em Educação da Universidade Federal de Juiz de Fora (UFJF); Doutor em Educação pela Universidade de São Paulo (USP); Especialista em Ciências Sociais (Antropologia, Sociologia e Política) pela Fundação Escola de Sociologia e Política de São Paulo (FESP-SP); Graduado em Filosofia pela Universidade São Francisco (USF-SP); Líder do ANIME (Grupo de Pesquisas em Africanidades, Imaginário e Educação); Membro da área "Filosofia Africana e Afrodiaspórica" da ABPN. E-mail: julvan.moreira@ufjf.edu.br

${ }^{5}$ Nasceu no Rio de Janeiro em 1972. Residente em Duque de Caxias é Professor de Filosofia do Departamento de Educação e Sociedade, do Programa de Pós-Graduação em Filosofia da Universidade Federal Rural do Rio de Janeiro. Atua como Pesquisador do Laboratório de Estudos Afro-Brasileiros e Indígenas (LEAFRO) e do Laboratório Práxis Filosófica de Análise e Produção de Recursos Didáticos e Paradidáticos para o Ensino de Filosofia da UFRRJ. Possui doutorado, mestrado e graduação em Filosofia pela Universidade Federal do Rio de JaneiroE-mail: renatonoguera@ymail.com

${ }^{6}$ Doutor em Bioética pela Universidade de Brasília (UnB). Professor de Filosofia e Bioética da UnB. Colíder do Grupo de Estudos e Pesquisas em Educação, Raça, Gênero e Sexualidades Audre Lorde (GEPERGES Audre Lorde UFRPE/UnB/CNPq) e Membro do Núcleo de Estudos Afro-Brasileiros (NEAB-CEAM/UnB) e do Núcleo de Estudos de Filosofia Africana Exu do Absurdo (NEFA/UnB). E-mail: wandersonn@gmail.com
}

Revista da ABPN • v. 12, n. $31 \cdot \operatorname{dez} 2019$ - fev 2020, p. 3-10 
pesquisas sobre as culturas africanas estão centrados nos campos da etnologia, da história e da sociologia.

O dilema da Filosofia Africana no Brasil permanece sobre a quem de fato é delegada a função de pesquisar sobre essa área e quem, de fato, detém maior conhecimento e habilidades sobre teorias e métodos filosóficos.

O que vai "sulear" esse dossiê temático é seguinte questão: qual o conhecimento que tem sido construído na área da Filosofia Africana no Brasil? Defendemos que todo pensamento filosófico parte da compreensão do que diz respeito à nossa humanidade e, nesse sentido, todos nós humanos, da filosofia, da educação, da antropologia, da psicologia, da arte, etc., temos o direito de falar sobre nossa condição, enquanto ser humano. Diante desse ponto de vista é possível pensar que cada pesquisador e pesquisadora, cada educador e educadora, cada professor e professora possui um saber filosófico sem o qual ele não poderia trabalhar, nesse caso específico, e que não pode ser facilmente refletido.

A Filosofia Africana é um campo de conhecimento que vem se consolidando no Brasil e os estudos apresentados nesse dossiê contribuem para essa produção, possibilitando interpretações, compreensões e reflexões sobre os diferentes sentidos e possibilidades do fazer filosófico a partir de distintas cosmopercepções africanas e afrodiaspóricas. Com isso, esperamos que as produções aqui apresentadas contribuam para a ampliação e aprofundamento dessa discussão no país, território notadamente marcado pela presença de ricas expressividades de matriz africana, cuja densidade filosófica ainda temos muito por aprender.

O artigo dos autores Emanoel Luís Roque Soares e Wanderson Flor do Nascimento, "Exu, corpo e sexualidade", analisa a relação entre corpo e sexualidade a partir das '21 faces de Exu” e suas múltiplas variações, com destaque para a versão feminina de Exu em terras brasileiras: a Pombagira. Revisitando as abordagens sobre "o dono do corpo", os autores colocam em cheque o patriarcalismo sexista colonial que as experiências de Exu e da Pombagira subvertem, seja na perspectiva masculina ou feminina. Desvinculando a sexualidade da procriação, temos uma configuração que não submete o corpo a um regime moralista e a um patriarcalismo arcaico. O corpo é território do prazer e o gênero não é ideologia de submissão. Ao contrário, o corpo é espaço de liberdade e o feminino-masculino que se apresenta é sob o signo da autonomia forjada na experiência negro-africana-diaspórica e nunca da fixação hierarquizante da sexualidade 
cunhada na matriz eurocêntrica. A potência de Exu e seus codinomes potencializa os processos educativos em termos próprios, autorreferenciados em nossa dinâmica diaspórica propiciando uma verdadeira epistemologia incorporada, onde o corpo não está submetido aos ditames da moral, da ciência ou da religião, mas tendo Exu como referência, é a livre expressão da sexualidade, da sensualidade e da liberdade prazerosa de ser quem e como somos. Exu, que abre os caminhos, abre também este dossiê temático.

No artigo "Filosofia africana desde saberes ancestrais femininos: bordando perspectivas de descolonização do SER-TÃO que há em nós", a professora Adilbênia Machado apresenta um diálogo com os saberes ancestrais femininos desde a filosofia africana com intuito de refletir acerca da descolonização do ser-tão que há em nós, tendo as filosofias da ancestralidade e do encantamento como os fios que tecem esses diálogos formativos. Partindo de saberes tecidos por mulheres negras que bordam experiências coletivas, irmanadas, ancestrais e encantadas, a autora expõe uma compreensão de nossos corpos como templos ancestrais, capazes de nos fortalecer coletivamente, nos encantando e lutando diariamente pela descolonização do ser-tão desde uma relação comunitária e ancestral, delineada pela natureza e o tempo. Dessa forma, o encantamento tecido pela ancestralidade é compreendido como um ato contínuo de transfor-AMAR e a filosofia africana como sendo oriunda desse encantamento.

Bas'Ilele Malomalo, em “A justiça teórico-política ao matriarcado para se pensar a África contemporânea", tem por base o conceito de matriarcado desenvolvido pela antropóloga, poeta e escritora nigeriana Ifi Amadiume, com objetivo de testar o poder teórico-político da categoria matriarcado diante de duas realidades, o Coletivo de Mulheres Africanas (CMA), da Universidade de Integração Internacional da Lusofonia Afro-Brasileira (UNILAB), e a violência sofrida pelas mulheres congolesas no leste do país, no contexto da guerra, de 1997 a 2003 e no período pós-guerra, de 2003 a 2018. O estudo desenvolvido por Malomalo revela que em muitas sociedades africanas, os sistemas culturais patrilineares coexistiram e coexistem ao lado dos sistemas culturais matrilineares. E, algumas culturas consideradas patrilineares mantêm muitos dos valores do matriarcado, e um desses valores é o respeito que todos os africanos, homens e mulheres, devem ter pelas mulheres, sejam elas mães ou não. Nesse sentido, o autor afirma que, do ponto de vista do matriarcado, há nos sistemas africanos de gênero a flexibilidade que permite a construção de um gênero neutro além de homens e mulheres, permitindo-lhes trocar seus papéis, ou seja, o princípio do duplo sexo por trás da 
organização social mediado pelo sistema flexível de gênero da cultura e linguagem tradicionais. As sociedades africanas baseadas no matriarcado ao tratar as relações de gênero com flexibilidade, além do sexo masculino e feminino, incorporam um terceiro que aceita a troca de papéis. Amadiume denominou esse terceiro sexo de "gênero flexível", que se manifesta através dos papéis desempenhados por "filhas-machos", que são as mulheres com funções masculinas e "maridos-fêmeas", que são os homens "esposas do rei". Com o Islã entrando no continente africano, em seguida o cristianismo e o estado ocidental moderno, o matriarcado africano entrou para a marginalidade e o patriarcado foi estruturado, gerando uma masculinidade africana tóxica. Conclui-se que este estudo sobre o matriarcado contribui para os recentes debates sobre a filosofia africana.

Por sua vez, "Práxicas afroperspectivadas e griotagens em educação", de Julvan Moreira de Oliveira e Jussara Alves da Silva, partindo de experiências pedagógicas afrocentradas, objetivam a viabilidade da formação docente levando em conta pedagogias afro referenciadas para a educação das relações étnico raciais na escola. Elegendo a formação de professores como lugar de discurso e a práxis docente como destino metodológico, valem-se da experiência da professora denominada Kadidja (em homenagem à mãe de Hampate-Bá), sobretudo no universo das brincadeiras e canções, para refletir, a partir da Pretagogia (elaborada por Sandra Petit), da Pedagoginga (proposta por Allan Rosa) e da Pedagogia Griô (sistematizada por Lilian Pacheco) práticas e reflexões (práxis) positivas para as crianças negras e não-negras. Julvan e Jussara identificam elementos fulcrais da cosmovisão e cosmo-percepção africanas que alimentam uma 'práxica' fundamentada na circularidade, memória, oralidade, sensibilidade, subjetividade, ancestralidade, entre outros, que perfazem um legado cultural africano e culminam nas práxis pedagógicas nutrindo-se dos saberes ancestrais, combatendo, assim, os currículos e metodologias eurocentrados, corroborando para a produção do conhecimento afro referenciado e no encantamento dos processos educativos tendo como dispositivo os conteúdos e formas da cultura africana e diaspórica. Enfim, não reduzindo, mas partindo das experiências da Professora Kadidja com canções e brincadeiras foi possível constatar, a partir das pedagogias supracitadas, uma práxica pluriversal e biocêntrica imantada no rico legado da cultura africana e seus saberes passíveis de presença constante em nossos currículos e metodologias. 
Laudemir Pereira dos Santos - Lau Santos, em seu trabalho intitulado "A filosofia do malandro: estéticas de um corpo encantado pela desobediência", tem como objetivo demonstrar que o jogo corporal, a maneira sincopada de agir e ser-no-mundo de um malandro é um ato de resistência contra o conhecimento hegemônico baseado na racionalidade. Esse conhecimento eurocêntrico nega todo o corpo como um dos lugares atravessados por grafias psicofísicas, que geram outras lógicas epistemológicas além do cartesianismo. A clássica separação entre mente e corpo, tão predominante no pensamento euro-ocidental, criou uma fenda ontológica entre o corpo e as lógicas socioculturais que atravessam esse corpo. O tema da astúcia é observado à luz dos princípios estabelecidos pelo jogo da capoeira e pela suavidade do corpo masculino no samba. A malandragem é vista como uma maneira filosófica de existir. Forma de produção da presença caracterizada no jogo do "eu" com o "outro", ou seja, na capacidade do sujeito de organizar seus movimentos psicofísicos, a fim de contornar as regras de conduta baseadas em orientações racistas coloniais, nas quais negro é representado como o protótipo de uma figura pré-humana, incapaz de escapar de sua animalidade. O corpo negro aprende elementos ancestrais, com os traços históricos de resistência ao racismo. Cada jogo em um círculo de capoeira são experiências únicas de uso do corpo, reconfiguradas com base nos princípios filosóficos da malandragem. Uma figura mítica da malandragem é Seu Zé Pilintra, devido a importância de seu comportamento como um ato de insubordinação e desobediência aos padrões comportamentais coloniais. Zé Pilintra desafiou a colonialidade e se impôs à imaginação do povo brasileiro. Capoeira, samba e outras danças negras, armas de resistência social e poética atravessaram o oceano durante séculos e, neste século XXI, fazem parte de pesquisas universitárias. Tudo isso acontece na fronteira que divide o material e o imaterial, o visível e o invisível, o fictício e o real. Evidenciamos, assim, que esse artigo provoca reflexões sobre o aspecto filosófico do jogo corporal do malandro como um ato de resistência ao conhecimento eurocêntrico hegemônico.

No artigo "Paisagens filosóficas africanas: filopoética da libertação como disputa de imaginário", Luís Carlos Ferreira dos Santos e Eduardo David de Oliveira têm o objetivo de problematizar a ausência do diverso na paisagem da produção filosófica e analisar a filopoética como disputa de imaginários. Para isso, os autores defendem as filosofias africanas como espaço de ampliação do filosofar. O percurso do texto se expressa em um filosofar desde a geopoética africana, no intuito de disputar imaginários,

Revista da ABPN • v. 12, n. $31 \cdot \operatorname{dez} 2019$ - fev 2020, p. 3-10 
traçar itinerários, rotas na conexão com o todo-mundo. O segundo momento problematiza a importância política de habitar e ser habitado pela própria paisagem; e, por fim, os professores apresentam uma defesa da filopoética da libertação como uma ferramenta nessa disputa, de modo que sua função é apontada no sentido de povoar o nosso imaginário e produzir mundos com liberdade, crítica e criatividade.

$\mathrm{O}$ artigo de Luís Thiago Freire Dantas, "O pan-africanismo em Abdias do Nascimento e a proposta de descolonização", discute a proposta pan-africana de Abdias do Nascimento como uma proposta política e epistêmica que dialoga com uma articulação teórica de intelectuais negros no continente africano e em sua diáspora que pode ser lida, em consonância com alguns intelectuais africanos e diaspóricos como uma importante ferramenta de descolonização do pensamento e das relações políticas atravessadas pelo racismo.

$\mathrm{O}$ artigo "Experiências afrorreferenciadas: a dança negra no ensino fundamental" de Magali Pinto aborda a necessidade de abordagens afrorreferenciadas no ensino da dança, apontando assim para a inserção de horizontes epistemológicos, políticos, metodológicos e estéticos na atividade da educação antirracista, que atenda às demandas da implementação do artigo 26-A da LDB, em sua dimensão da história e cultura africana, afro-brasileira e indígena, na busca do reconhecimento e fortalecimento da diversidade cultural, por meio de lógicas outras de pensar as relações entre arte e corporalidade na educação.

O texto "Sobre as possibilidades de realização da filosofia africana e a crítica da negritude senghoriana segundo Marcien Towa", de Roberto Jardim da Silva, apresenta o pensamento de Marcien Towa, começando com a definição do que é a filosofia, em que ele diz que todas as pessoas, de todas as culturas e etnias são capazes de desenvolver um pensamento filosófico, desde que elas estejam prontas para pensar o absoluto, livres dos vínculos dos dogmas ou de qualquer outra doutrina que os impeça de se tornarem críticos e livres para pensar. Com base nesse quadro de liberdade de pensamento, Towa também define a filosofia em oposição à religião, mito e ciência. Em seguida, ele critica a etnofilosofia e o conceito de negritude senghoriana e problematiza a discussão sobre a rejeição da cultura europeia, proposta pelos etnofilósofos, como um problema que se apresenta como um obstáculo à realização da filosofia africana. Finalmente, Towa enfatiza a racionalidade presente na cultura africana baseada na estrutura dos contos camaroneses e na religião do Egito antigo e indica os possíveis 
caminhos para a filosofia africana. Este estudo mostra que, em sua busca pela disseminação da filosofia como forma de conhecimento, Towa busca compará-la à ciência. Ao contrário do pensamento mítico e religioso, a ciência é caracterizada pela observação, medição e experimentação. É preciso apenas a verdade o que é provado por sua metodologia, e o que a diferencia da filosofia é sua neutralidade. A filosofia já intervém na realidade social, política e econômica, cultural. Towa dá um passo para superar a etnofilosofia e a negritude pensadas pelo senegalês Léopold Sédar Senghor. Quanto à negritude, é um conceito que busca aprimorar a cultura negra de africanos e negros na diáspora. A ideia era reformular a palavra negro, dando-lhe um significado positivo, ou seja, negritude é a palavra usada para expressar orgulho em ser negro. E a etnofilosofia toma como filosofia, a cultura em todos os seus componentes, mitos, contos, provérbios, magia, cosmogonia e sabedoria. Assim, a etnofilosofia seria a filosofia dos sistemas coletivos de pensamento, tradições de pensamento, ou seja, visões do mundo. No entanto, Towa não rompe com a estrutura dualista e universalista que o pensamento africano herda do pensamento europeu. Pensadores africanos mais contemporâneos falam de uma filosofia que tenta romper com o dualismo, sugerindo um caminho diferente, no qual é guiada pela concepção de que não existe uma filosofia africana ou europeia pura. Uma maneira de fazer isso é olhar para o futuro, não considerando o período colonial como referência ou a Europa como referência para o desenvolvimento da filosofia, mas toda a humanidade em sua constante troca de conhecimentos.

$\mathrm{O}$ artigo de "Parangadinkra: potencialidades pretagógicas, ensinamentos e filosofias de três adinkras do povo Akan em Gana" de Sandra Petit e Wagner Ventura nos apresenta o conceito de Parangadinkra, um objeto estético-pedagógico que inventados para envolver Universidade e Escola com as oralidades e filosofias africanas tradicionais, ainda pouco exploradas como fonte e produção de conhecimento nas escolas, quer seja por preconceito ou desconhecimento. Interessam mais particularmente os ideogramas ganenses chamados adinkra que transmitem valores ético-estéticos filosóficos do povo Akan em Gana. Com isso, a autora e o autor esperam: 1) mostrar que a linguagem desses símbolos tradicionais também faz parte do conceito amplo de oralidade de Hampâté Bâ, 2) que abre uma riqueza de possibilidades de uso didático educacional, que pode ser potencializada por afrorreferenciais como a Pretagogia.

No artigo "Esboço de um programa de justiça comunitária libertária Ubuntu”, o professor de filosofia do direito Sérgio São Bernardo apresenta as 
civilizações africanas e afro-brasileira como detentoras de repertórios jurídico-filosóficos que podem mobilizar novas leituras de mundo para a prática da justiça e do direito numa dimensão local e global. Através do estudo da justiça e do direito o autor localiza valores, postulados, princípios, axiomas e provérbios presentes nas civilizações africanas e afrodiaspóricas, de modo a confrontá-las com os estudos e práticas sociais de justiça restaurativa, comunitária, autoridades tradicionais etc., tendo em vista a instituição de um campo de estudo para um Programa de Justiça Comunitária Libertária Ubuntu inspirado no pensamento afro-brasileiro.

Por fim, temos uma entrevista com o filósofo moçambicano, Severino Ngoenha, realizada por Eduardo Oliveira, que nos brinda com uma reflexão sobre as relações entre as realidades nacionais, as demandas políticas e a filosofia, além de discutir as parcerias possíveis entre os pensamentos moçambicanos e brasileiros.

Concluímos que a Filosofia Africana estudada no Brasil apresenta questões abertas, demonstrando que não existe um conhecimento definitivo sobre a área, pois ainda está num processo de construção, reconstrução e desconstrução do pensamento africano e afrodiaspórico em terras brasileiras. E já podemos perceber, na recente história da filosofia africana no Brasil, que ela se afirma por dentro de sua diversidade: pode-se dizer que temos múltiplas perspectivas na produção da filosofia africana, com matizes diversas, que cobrem um amplo leque de preocupações e criatividades. O diálogo, ainda, com a própria região (América Latina), internamente com praticamente todas as regiões do Brasil, e do Brasil com países africanos, apontam a robustez do que se vai constituindo sensivelmente como filosofia africana entre nós.

Em tempo, este dossiê, temático, embora formalmente organizado por cinco pessoas é produto de um esforço coletivo da área de Filosofias Africanas da ABPN, e todas e todos estão, de algum modo, enredados em sua construção. Nossos agradecimentos à área e, também, à Rede Africanidades são imensos.

Desejamos uma excelente leitura! 